\title{
Socio-cultural identity in the existential perspective The context of intercultural education
}

A B S TRACT: The article presents the issue of identification with groups of a cultural nature. The need to belong to a community is considered as one of the fundamental existential issues. In solving the dilemmas that arise in this context, the key role should be played by pedagogy. The involvement of pedagogy in this task should be connected with the recognition of a clear humanistic axiology taking into account the equality of existence of the communities created around various (different from each other) sets of cultural symbols.

KE Y W ORD S: Socio-cultural identity, existence, cultural community, intercultural education.

For three decades, the social and socio-cultural identity has been an important subject of interest for representatives of social sciences. Among them there is an increasingly significant voice of academic pedagogy. In view of the changing character of identity and its dynamics, the vision of desired conditions is not without significance. From the very beginning it should be noted that the issue does not concern any specific matrices. Rather, it is about its general character, its specificity taking into account the current situation of humanity. Identity in the pedagogical perspective should create a sense of security of the individual, but it should also, in the spirit of humanism, open the perspective of coexistence for people located outside the groups constituting a point of reference for the self-identifying individual. The temptation to perceive identity $\mathrm{o} \mathrm{nly}$ in a flickering vibration is particularly dangerous exactly when we look 
at it from a pedagogical perspective. A pedagogue should not only be aware of the essence of identity, its shape, dynamics (along with its critical turning points). Their responsibilities also include seeking ways to overcome problems that lead to changes in both the forms of identity as well as its content.

In relation to the socio-cultural identity, pedagogy - by its very nature - cannot remain only with a more or less passive description. The role of a pedagogue, or perhaps even their mission - no matter how unpopular it may be today - is to show the way, to shape the vision of the development of humanity on the basis of a reasonable extrapolation of the current spiritual heritage of mankind. In this context, identity cannot be treated as a tool for the strict preservation of the status quo, but it also cannot be an amorphous alibi for all man's attempts to escape from the conscious identification of their place in culture. Identity should therefore be a compromise between extreme conservatism and extreme progressivism, a mediator between stability and changeability, a catalyst for development and self-fulfilment.

In the optics presented here, I would like to focus on socio-cultural identity. In this context, a person perceives themselves as a member of groups that are bound together by a community of cultural values and are the emanation of their symbols. These symbols, in turn - internalized during the process of education - are an important condition for interaction and communication. Belonging to a group is a very important existential factor. As a social being, man actively seeks for groups of reference in which they could satisfy their needs, both the basic and the higher ones related to self-fulfilment and affiliation. They want to feel that they belong to these community groups, with greater or lesser intensity. The historical and cultural conditions for the transformation of communities were discussed, inter alia, by Tadeusz Pilch. At the same time, he drew attention to the importance given to the imaginary communities by contemporary people (Pilch 2010, p. 71).

One of the types of communities are communities built on the basis of the symbolic culture. They are created by people's use of the same set of symbolic measures available to them, one of which is language. It is language that to a great extent generates both similarities and differences between groups. Speaking different languages - from dialects, vernaculars, slangs to national languages or languages of the past cultures (Latin, Greek) - allows people to exist in many cultural spaces and communities. It is worth to quote here the well-known saying: "as many languages you know, as many times you are a human being".

If, after Antonina Kłoskowska, we accept the distinction between cultural identity and cultural valence (Kłoskowska 1996), it is worth to note the 
possibility of the occurrence of labelling. This kind of a sense of belonging to a group has a routine and habitual character. The identification of an individual in such cases results from the non-reflectively deepened ritualism. The identities based on such identifications are often the result of ideological indoctrination. In relations with cultural differences, people who label others are characterized by rigidity and hermeticity. In a conflict situation, on the other hand, the activation of defence mechanisms often results in aggression. The situation is different in the case of identification linked to an internalized cultural heritage. Such socio-cultural identity, based on reflectively developed symbolic resources, i.e. cultural valence, offers the possibility of existential deepening and, in relations with cultural differences, has the desired flexibility and openness.

It is in this context that we can see more and more clearly the existential context of identity. In this text I would like to refer first of all to the reflections of Anthony Giddens, who from this perspective presents the issue of identity at the end of the modern era (Giddens 2010). It seems particularly important to consider the interactive approach in solving human existential problems. It results from the assumption that basic problems of existential character are solved by man in contact with other people. Fundamental existential dilemmas have been rooted in interaction since the dawn of mankind. The evidence of this is the work of Sören Kierkegaard titled: Bojaźn i drżenie. Choroba na śmierć [Fear and trembling] (Kierkegaard 2008). The biblical sources, in existential contexts of constructing cultural identity, are referred to by the contemporary Israeli philosopher Avi Saga (Saga 2015). In everyday practice, this successful interaction reduces anxiety, which takes on different faces depending on the age of the person and the density of the interactive network in which they are entangled. However, regardless of age and life experience, the antidote to human existential problems, most often is another person.

The responsibility of tutors for shaping the socio-cultural identity of young people is confirmed by Giddens' opinion, according to which identity arises from the basic trust that a young child develops in relations with their family. This basic trust is even a condition for the development of one's own individual identity, but also for shaping the identity of other people (Giddens 2010, p. 59). It is the result of the care of the first tutors and constitutes a source of courage of existence for the child. As stated by Giddens, "the path to realize the independent identity of caregivers leads through the acceptance of "absencje " and consists in the development by the child of a »belief " that the caregiver will return even though they are not there now" (Giddens 2010, p. 64). Thus - paradoxically - it is this absence, which is initially a cause for 
fear and then a direct cause of emerging trust, it also becomes a source of a sense of continuity, one of the main attributes of individual identity.

Another important issue that needs attention is the sense of security of the individual. Giddens, quoting the opinions of Harry Sullivan, an American psychologist active in the mid-20th century, points out that the need for security appears very early in a child's life and it is much more important for man than even the impulses resulting from hunger or thirst. The child owes the early sense of security primarily to the care of the caregivers. An unusual role is played here by acceptance or lack of it. "The fear of a child who has not yet developed conscious reactions to the disapproval of others is a response to the lack of acceptance by the caregiver. [...] Accumulating fear often threatens the sense of one's own identity, because it obliterates the awareness of oneself in relation to the constitutive features of the objective world. The individual experiences themselves thanks to the cognitive relation to the world of people and objects (underlining added). This relationship is always based on the system of basic security, which is the source of basic trust around which cognitive structures are butli" (Giddens 2010, p. 64).

The question may be asked whether and to what extent the basic trust is shaped by cultural factors. Going a little further, we could ask what role do cultural conditions play in creating an objective world that determines human identity? Undoubtedly, this is largely determined by reflectiveness. This engagement of deepened consciousness in discovering the surrounding reality effectively leads to observing its cultural character. From the moment we consciously recognize the essence and meaning of: people, places, situations as anchors of culturally inherited values, we can clearly associate these people, places, situations with the sense of security that they bring us. In other words, we create a network of basic trust, the basis of which are symbols internalized in the processes of interaction of a pedagogical nature. These symbols are most often in the form of words of natural language. The first and at the same time the most important of them is the word describing a mother. A child develops an association of this word with a sense of trust. Trust is henceforth activated by the symbol - the word - alone.

Elementary trust is also related to upbringing in the family. The sense of security results from the way of functioning of the family. The relations between family members, especially between parents, are important. Another very important symbol that appears in the consciousness of a young person is home. In normally functioning families, the home becomes a haven of security, an existential support for the entire life. However, unlike the more natural relationship with the mother, the vision of home has a more cultural 
character. Basic trust will be related to the vision of the home that is built on family interaction. The problems that arise from this appear not only when we leave "our home" for the first time for a long time and find ourselves in relationships with other people that bring uncertainty and fear, but also when we unite with another person creating a marriage and then a new family. This is when two visions of the home often meet. In reality, the lack of support for a childhood vision of home becomes a source of existential tensions, leading in extreme cases to the break-up of a relationship. A special case here is the multi-generational family. The more important a role is played by tradition in the life of an individual, the more important intergenerational relations are. The cultural authority of grandparents, recognized by parents, becomes a solid element of the sense of security of the representatives of the generation of grandchildren. Rootedness gives a sense of permanence of reality, despite the awareness of historical cataclysms. Genealogical awareness is an important family-related element of building basic trust. In this case, we can speak about the cultural microclimate of the family. Owning and passing on family memorabilia from generation to generation is an important part of this microclimate. Cultural artifacts, such as old photographs or objects of everyday use used by ancestors, become symbols of durability and strength of the family. They provide a strong identity support. Often it is the grandparents who create a bridge between tradition and modernity, filling the gap between the destroyed cultural identities of the parents. Such a situation often occurred under conditions of intense indoctrination in former socialist countries. It was the grandparents who became the depositories not only of ethos and values, but also of cultural symbols that were their carriers.

Leaving the family, people often seek support in strictly cultural groups. Such support is very closely related to very intense problems of existential nature. It is not uncommon for a young person to break all ties with a family if they do not have any support there. In the period of adolescence they find answers to their questions in peer groups, religious groups or groups with distinctive sub-cultural features. It is the degree of reflectiveness that determines the quality and depth of the search. Sometimes a sufficient motive is the existence of distinct external attributes of a given community. Such a situation occurs in the case of most youth sub-cultures. Sometimes more serious dilemmas lead young people into very dangerous, destructively influencing their identity, parareligious groups. Sometimes the search for the purpose of life, ineffective within the existing cultural systems, results in rather risky decisions leading to religious conversion. This usually happens when young people are not culturally rooted in the religious tradition of their ancestors, 
i. e. the tradition is not internalized. Deep existential dilemmas are then met with a shallow, superficial attitude towards the sphere of religiousness. The traditionally legitimized rituals do not constitute a sufficient barrier against conversion. The glare of otherness, usually in a simplified form, is sufficient for a radical change. Regardless of civilizational changes and the degree of social development, the sphere of the spiritual life and the closely related issue of belonging to specific religious formations, in our part of Europe, will always be a very important area of existential tensions and the subsequent selfidentification. Hence the great importance of religious identities in the profile of socio-cultural identity of young people.

Through formal education, young people in Europe are incorporated into the specific reality of the nation state. Therefore, they are obliged to take a position on the issue of their belonging. Especially since most of the communicates speak of "our national culture". They have to answer the question whether the national culture, discussed in the textbooks, is "their" culture? It is a matter of elementary, fundamental identification with a macro-cultural group which, since the Enlightenment, has been one of the main points of reference in European culture - with the nation. It is important to distinguish whether we are talking about a nation as a territorial political community or a community based on a relatively coherent cultural symbolic universe. Although they are so distinctly different, the two terms are sometimes used interchangeably, which causes many misunderstandings and undesirable pedagogical effects.

In the situation of the intensely discussed issue of the nation state, it seems important to devote a few sentences to this topic. First of all, the Enlightenment paradigm of education, in which the content related to the nation is an important part of the core of educational interactions, is still valid. There is also no evidence that anything radical in this respect could happen in the near future. Secondly, intensive migration processes and the phenomena of spectacular national conversions of a mercantile nature create more and more situations in which this issue becomes a subject of public discussion. Hence, one cannot abstract from self-determination in this area. National identities have and will have an important place in the profile of socio-cultural identification of an individual. Based on this assumption, it should be emphasized that one can describe oneself as a Pole in terms of a political community, that is as a citizen of a country called the Republic of Poland. Although the granting of citizenship is connected with the fulfillment of basic requirements defined by law, reality shows us that it can be treated flexibly. Such is the case with well-known athletes, who recently very easily obtain citizenship of another country. 
The second dimension - independent of the first one - is an individual's self-assignment to the nation in cultural terms. Awareness is essential in this case. Both a reflective embrace of the cultural community as well as a willingness to identify with it or, going further, a willingness for the internalization of the cultural heritage of that community, must occur. One needs to realize that such a thing as the culture of a national community does exist. It is necessary to know what constitutes this phenomenon, but also to be willing to make it part of the own "self". We are dealing here with a conscious rooting in the national cultural heritage.

Of course, building a conscious and deepened sense of belonging to culture in the national dimension is a complex process. An important element of it is the reference to canonical values and symbols that represent them. The cultural canon constitutes the core around which identities are built. Of course, the canon is constantly evolving, although its substantial part is very solid. It is this part that constitutes the space with which the main processes of integration of the national group are connected.

Both aspects of identification with the nation (political-citizenship and cultural-symbolic) can occur simultaneously. And in the vast majority of cases both of them characterize people who feel Poles. However, such unity does not always appear. Some people who feel that they belong to a Polish cultural community, in extreme situations in the relatively recent past, questioned Polish citizenship. This was the case in the times of Poland's dependence on the Soviet Union. Emigration was a very frequent choice in such cases. In turn, people belonging to national minorities identify themselves with the cultures of their home countries. Many inhabitants of Puńsk culturally consider themselves Lithuanians, but taking into account the criterion of citizenship Poles. The lack of a clear distinction between the two perspectives in the situation of the need to make a statement of belonging leads to the necessity of choosing, characterized by strong existential tensions.

The situation is made even more complicated by the fact of coming from mixed families or, more generally, by the awareness of the cultural heterogeneity of their ancestors. In such a situation, even in the sphere of belonging to the nation as a cultural community, it is difficult to make unequivocal declarations. The stronger the mutual cultural influences, the more difficult it is to be unequivocal. The greater are the challenges for researchers of the problem and people accompanying in the process of education in shaping the identity of young people. It is especially important not to simplify the reality by adapting it to the patterns existing in the social space, but rather to saturate it with deep reflectiveness. This is an extremely important task, because in the conditions of 
intense diffusion of cultures, socio-cultural identities are at the very center of existential dilemmas. Especially in the late adolescence period, cultural groups are an important area for building basic trust.

Due to the importance which the educational system attaches to belonging to a national community and in connection with the events of the last two centuries, which have been particularly tragic in Europe in terms of national issues, the determination of ethnicity - especially in the area of diffusion of national cultures - is an important existential issue today. It also increases the possibility of traveling within much of the European continent. The socio-cultural identity, however, in each of its dimensions, is activated by contact with "the other".

Giddens' cardinal statement is that man "answers" existential questions "simply by "doing" everyday life, by the type of activity they carry out" ( Giddens 2002 , p. 68 et seq.). This means that the answers to existential questions are at the behavioral level. It is in the conscious interactions that the trajectory of our identity is formed. The task of educators is to awaken awareness of the multidimensionality of socio-cultural identity, also making young people aware of the existence of internal heterogeneity of socio-cultural identity of each person. Through appropriate interactions one should aim at a balanced profile, in which national identities are balanced by the awareness of the existence of other narrower and broader cultural groups - such as a region or Europe. Not without significance is also the recognition of the $\mathrm{cultural}$ dimension of religion. Multidimensional socio-cultural identities must be complemented by corresponding valence spaces. The lack of reflective support in the cultural heritage of the community may lead to labelling, which results in defensive mechanisms related to the sense of threat from "culturally different" people. Such a threat is often related to the lack of support on a solid, internalized foundation in socio-cultural self-definition. Uncertainty resulting from the lack of rooting in a particular cultural space is one of the basic sources of fear of the contemporary man, freely surfing the Internet.

The contemporary whirlwind of everyday life is increasingly generating existential dilemmas regarding the basic dimensions of human life. The necessity to deal with them concerns every person who tries to do well in the conditions of the decline of the modern world. As noted by Giddens, such existential dilemmas include not only those concerning the essence of being and the nature of existence, but also those resulting from the connection between the outside world and human life, and those arising from the significance of the existence of other people for our own existence. 
Other people are fundamental to our identity, especially the sociocultural one. Hence the interactive nature of identity. This is why Giddens' opinion that "self-awareness does not take precedence over the awareness of others and intersubjectivity does not derive from subjectivity; it is quite the contrary" is so important. (Giddens 2010, p. 72). The cultural subjectivity of each of us is to a large extent a result of the influence of other people.

What, therefore, is the socio-cultural identity of an individual? Above all - as in any other context - its fundamental feature is reflectiveness. Identity is a reflective awareness. Socio-cultural identity of an individual does not have a genetic nature. By its very nature, it must be permanently created and maintained by a $\mathrm{reflectively}$ functioning individual. Although identity - including socio-cultural identity - presupposes continuity in time and space, the most important is the fact of a reflective interpretation of this continuity by the individual. The source of this interpretation is in the cognitive side of being a person. The idea is not only that the individual is a reflective social actor, but also operates within the concept of a person. Hence the ability of all known cultures to use the expression "I" in changing contexts is an elementary feature of the reflexive concept of theself, also in cultural contexts.

It is also worth to stress that the socio-cultural identity of an individual depends on their ability to con $\mathrm{tin}$ u e a specific narrative. The individual constantly incorporates into their biography current events from the outside world, which they arrange into a continuous "history" about themselves. Hence the often mentioned postulate to treat identity in such a way that we take into account both the heritage of the past and the requirements of the present, as well as the expectations of the future. According to Charles Taylor, "in order to have some idea of who we are, we must have an idea of how we have evolved and where we are going" (Taylor 2001, p. 94).

According to Giddens, a person whose identity is relatively constant, first of all - has a sense of biographical continuity, and therefore is able to reflect on the course of their own life and, more or less exhaustively, describe it to others; secondly - has a sense of self-esteem; has enough self-respect to maintain the feeling of being alive, i.e. of reflectively controlling reality rather than merely being its inert element; and thirdly, through early relationships of trust, has developed a protective cocoon which, in everyday life situations, isolates this person from the influence of factors that may violate the integrity of identity and threaten their self-esteem (Giddens 2010, p. 76).

All three aspects can be linked to socio-cultural identity, which includes all important dimensions of involvement of the individual. Cultural 
biographical awareness, the ability to reflect on it and the resulting sense of self-esteem create a specific protective cocoon that helps to reduce existential fears. Only in a situation when we are able to handle ourselves can we be open to a culturally different person. Only then does the attitude to cultural difference have a chance to go beyond the narrowly understood tolerance, where we barely "stand" someone who differs in their cultural functioning from what we are familiar with from our own reference groups. This is where we come to the very essence of intercultural education. A wise opening to otherness that bears the signs of cultural symbiosis is not possible when we feel identity-related, deep existential fears. In such a situation, the "opening" is at risk of either defensive stiffening, connected at least with the activation of stereotypes, or conversion. For obvious reasons, neither is desirable. That is why the influence aimed at strengthening the awareness of multidimensional identity, which will allow to avoid existential fears and make wise use of cultural pluralism, is so important.

\section{References}

Giddens A., 2010, Nowoczesność i Tożsamość. „Ja” i społeczeństwo w epoce późnej nowoczesności, PWN, Warszawa.

Kierkegaard S., 2008, Bojaźń i drżenie. Choroba na śmierć, Wydawnictwo Homini, Kraków. Kłoskowska A., 1996, Kultury narodowe u korzeni, PWN, Warszawa.

Pilch T., 2010, Od wspólnoty do osamotnienia, [in:] Edukacja społeczna wobec problemów wspótczesnego świata i społeczeństwa, eds. J. Piekarski, T. Pilch, W. Theiss, D. Urbaniak-Zając, Wydawnictwo Uniwersytetu Łódzkiego, Łódź.

Sagi A., 2015, Existentialis, Pluralism, and Identity, Brill, Leiden, Boston.

Taylor Ch., 2001, Źródła podmiotowości. Narodziny tożsamości nowoczesnej, PWN, Warszawa. 